\title{
Riqueza en suelo eriazo. La industria guayulera y los conflictos interregionales de la elite norteña en México
}

Al despuntar el siglo xx la naciente industria del caucho acarreó consigo un acelerado desarrollo técnico, agrícola, industrial y comercial. Los grandes intereses creados encontraron en el norte de México una fuente adicional de abastecimiento a partir del guayule, desatando una dura competencia por su control y convirtiéndose en causa de grandes disputas entre terratenientes, empresarios nacionales, extranjeros y pueblos.

INTRODUCCIÓN

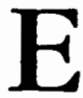

n las postrimerías del siglo XIX y principios del $\mathrm{xx}$, ocurrieron cambios profundos en el campo duranguense, destacando dos zonas al este de la entidad -la de los valles y la semiárida- que reunieron todas las condiciones propicias para el despegue de una economía que apuntó, preferentemente, a mercados externos en expansión tanto agrícolas como industriales. En los valles existían suelos de calidad excepcional cruzados por ríos y arroyos, con extensas llanuras que preservaban ricas praderas donde pacían los abundantes ganados lanar y cabrío, parte esencial de la prosperidad de las fincas ahí alojadas. La región semiárida contaba con haciendas dedicadas también a la industria pecuaria y al aprovechamiento de diversos productos naturales. En esta área, la parte más ricamente aprovechable para la agricultura fue La Laguna, punto en el que convergen los ríos Nazas y Aguanaval.

En los partidos de Mapimí, Cuencamé, Indé, San Juan de Guadalupe, Nazas y San Juan del Río, ${ }^{1}$ la agricultura,

${ }^{1}$ Véase mapa de la división territorial de Durango en el artículo de Graziella Altamirano en este mismo número de Secuencia. 
la minería, la ganadería y el comercio alcanzaron un gran dinamismo al entrar a la órbita de La Laguna, región que atrajo grandes capitales gracias a la confluencia de una bien distribuida red ferroviaria y a las modernas innovaciones que optimizaron los procesos productivos. En ese sentido, aquellos partidos se orientaron a producir, en primer término, algodón, el cual favoreció muy directamente el establecimiento de fábricas textiles y empresas que industrializaron íntegramente su semilla. ${ }^{2}$ Sin embargo, numerosos inversionistas llegaron a La Laguna con la finalidad de explotar un producto nuevo y con altos rendimientos en los mercados internacionales: el guayule. ${ }^{3}$ Su aprovechamiento industrial -como fuente productora de hule- se inició en México a principios del siglo $\mathrm{XX}$, no obstante que desde el $\mathrm{XIX}$ se conocían las propiedades del arbusto (véase mapa 1). La expansión de la industria guayulera en México corresponde al periodo 1903-1921, dentro del

\footnotetext{
${ }^{2}$ El algodón había adquirido importancia en el estado de Durango desde mediados del siglo XIX. Su rápido desenvolvimiento se debió a múltiples factores, entre ellos el almacenaje del agua del Nazas mediante presas y canales, que hicieron de la fibra el primer producto agrícola del estado. Véase Cano y Vallebueno, "Campo", 1995, pp. 59-85.

${ }^{3}$ El guayule es una planta que se localiza principalmente en los estados del norte de la república mexicana y es de gran importancia industrial porque contiene un látex que sirve para elaborar hule, en sustitución de otras plantas cauchíferas. Desde principios del siglo xx y hasta después de la segunda guerra mundial, un porcentaje importante del hule industrializado provino del guayule, que luego cayó en desuso tras inventar los alemanes el hule sintético
}

cual pueden considerarse como años de mayor auge 1909-1911.

El decidido apoyo que el gobierno de Porfirio Díaz dio a la inversión extranjera coincidió con las condiciones que, a nivel mundial, impulsaron la entrada masiva de capitales extranjeros. A diferencia de los cultivos destinados a la exportación, localizados principalmente en Morelos, península de Yucatán y norte del país, el sector agrícola, sobre todo el de los alimentos, permaneció, con ciertos matices, estancado. ${ }^{4}$

La demanda de llantas neumáticas entre 1875 y 1910 estimuló el consumo mundial de caucho, cuyo precio fue en ascenso, con lo que se alentó la búsqueda de nuevas fuentes de abastecimiento. En México, químicos e inventores, algunos comisionados por el Departamento de Fomento, comenzaron a buscar un procedimiento para extraer el caucho del guayule. Después de 1903, algunas empresas privadas comenzaron a explotar tierras guayuleras y a enviar a Alemania el producto para su procesamiento. El inmediato éxito económico encontró respuesta en el gobierno de Porfirio Díaz, que fijó un impuesto a la exportación de quince pesos por cada tonelada de materia prima, iniciando así el auge del guayule.

\footnotetext{
${ }^{4}$ El requerimiento de materias primas por parte de los países más desarrollados posibilitó que México se incorporara como abastecedor; en 1877 el valor de las exportaciones ascendió a 40000000 de pesos, en 1910 a 288000000 y la tasa acumulativa de las exportaciones fue de 6.1\%. Los principales productos de exportación en este último año fueron caucho, henequén, café y pieles de ganado vacuno. Véase Cosío, "Historia", 1974, pp. 635-639.
} 
Mapa 1. Distribución geográfica del guayule en México

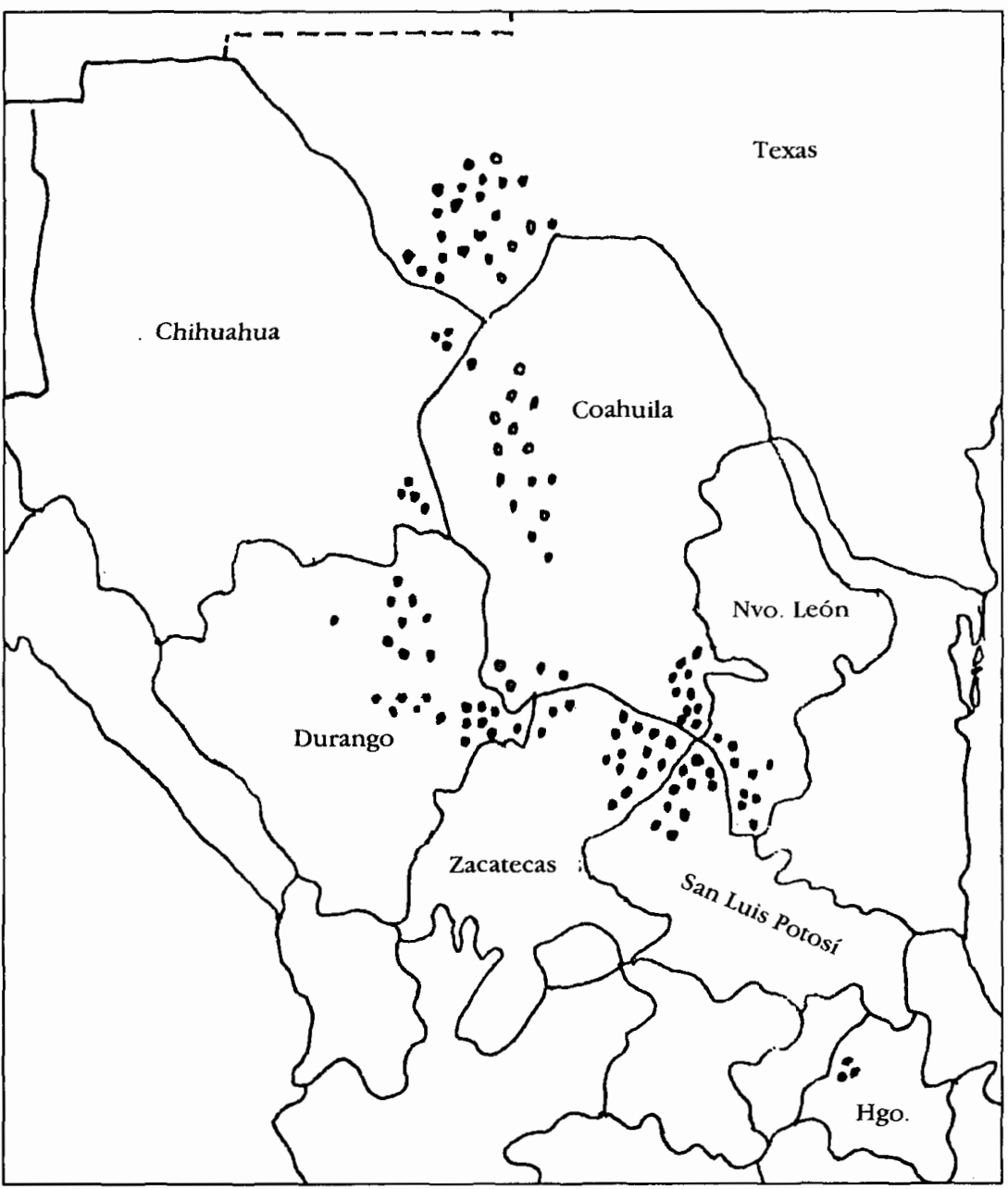

Fuente: Guayule, s.a., p. 205. 
Entre 1902 y 1912 se instalaron en La Laguna alrededor de 16 compañías guayuleras. El número de empresas estuvo relacionado con la importancia y los requerimientos mundiales de hule; la presencia de grandes capitales extranjeros muestra la gran competencia que se desató en nuestro país por controlar esa importante rama de producción y con ella el mercado.

\section{LOS INVERSIONISTAS}

1902 marca el año a partir del cual se inicia el establecimiento de una serie de empresas guayuleras en las que inversionistas nacionales y extranjeros tendrían una intensa, breve y muy redituable relación con dicha industria (véase gráfica 1).

La primera sociedad constituida -20 de agosto de 1902- fue la Compañía Anglo Mexicana, ${ }^{5}$ establecida en la hacienda La Flor de Jimulco, Coah., propiedad de Amador Cárdenas, uno de los más prominentes hacendados de la región, cuyo latifundio estaba integrado por los siguientes anexos: La Trinidad, Pozo Calvo, Juan Eugenio y Jalisco, pertenencientes al municipio de Torreón, y Sombreretillos, Nazareno y Picardías, pertenecientes a Durango.

El contrato de concesión que obtuvo del gobierno local le otorgó exención de impuestos municipales y estatales por ocho años al capital invertido en la explotación de guayule y en la instalación de una planta industrial

\footnotetext{
${ }^{5}$ Archivo General de Notarías (en adelante AGN), protocolo del notario Manuel Borja Soriano, 20 de agosto de 1902.
}

para su procesamiento. Poco tiempo después, el 7 de julio de 1904, se fundó la Compañía Explotadora de Hule, S. A., cuyos accionistas mayoritarios eran los hermanos Jacinto y Fernando Pimentel y Fagoaga, propietarios de la hacienda de Melilla, cuyos terrenos estaban comprendidos en los partidos de Cuencamé y San Juan de Guadalupe, Dgo. ${ }^{6}$ La empresa tuvo como propósito original desarrollar un invento patentado por el ingeniero Elías Delafond para extraer caucho y utilizar los residuos como pasta para elaborar papel, de manera que los primeros pasos se encaminaron al aseguramiento de la materia prima, estableciendo contratos de compra con productores en Durango y Coahuila. De hecho, la Explotadora de Hule no pudo iniciar formalmente sus trabajos sino hasta enero de 1906 , pues su propósito de establecer una fábrica procesadora en Cuencamé no prosperó, decidiéndose su construcción en Torreón, Coahuila.

El licenciado Práxedis de la Peña formalizó la Compañía Coahuilense, S. A., el 23 de octubre de 1905, con el objeto de explotar el guayule de la hacienda Gruñidora perteneciente al partido de Mazapil, Zac., donde existía el propósito de establecer una fábrica procesadora. Esta empresa se inició como un negocio mayoritariamente familiar, ${ }^{7}$

${ }^{6}$ Ibid., protocolo del notario Jesús Trillo, 7 de julio de 1904

${ }^{7}$ Registro Público de la Propiedad (en adelante RPP), Registro público del comercio, 1905, insc. 54. En el Consejo de Administración figuraban: presidente, Práxedis de la Peña; secretario, Mauro de la Peña; primer vocal, Emilio de la Peña; segundo vocal, Práxedis de la Peña (hijo); tesorero, Óscar Francke. 
告

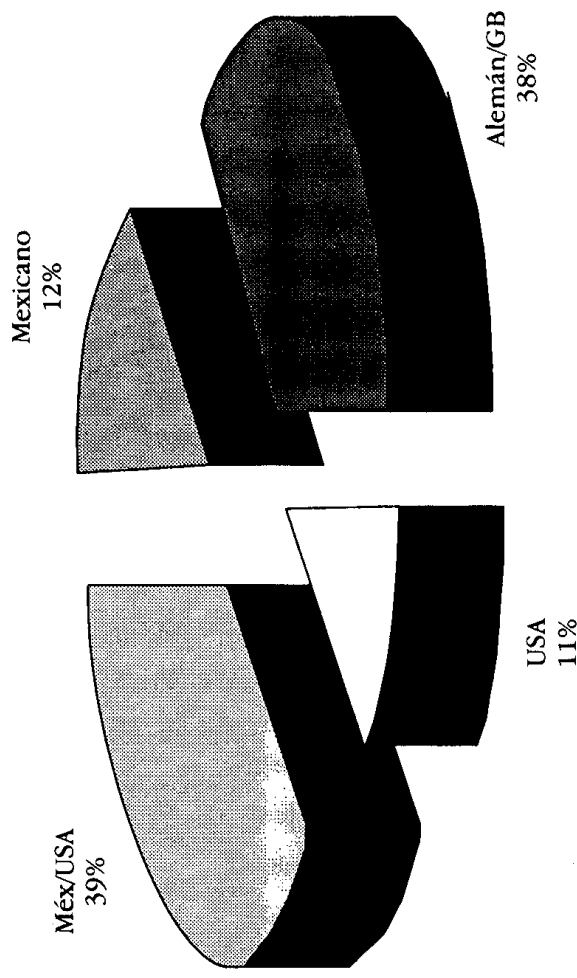

告 
aunque poco después perdió dicho carácter.

Una de las mayores inversiones en el negocio guayulero ocurrió el 29 de noviembre de 1905, cuando el señor Adolfo Marx, Rosie F. de Marx, el Dresdner Bank de Berlín, el Deutsche Effecten Wechsel Bank de Franckfurt y Landauer y Cía., de Londres, constituyeron una sociedad bajo la razón social Adolfo Marx, Sociedad en Comandita que, para 1910, habría de cambiar a Compañía Explotadora de Caucho Mexicano, S. A. ${ }^{8}$ La organización de esta empresa ejemplifica su manera de operar en el país: desde luego el objeto era adquirir o arrendar terrenos en los cuales se produjera guayule; comprar u obtener privilegios o contratos otorgados por los gobiernos estatales o federales. Asimismo, aprovechar patentes de procedimientos químicos y mecánicos para la extracción de hule. La compañía fue eximida del pago de impuestos por un periodo de diez años.

La Anglo Mexicana quedó incorporada a la Compañía Explotadora de Caucho Mexicano S. A., aportando con ello su franquicia de impuestos, un contrato con la Mazapil Copper Company y la fábrica La Guadalupana, S. A., establecida en San Luis Potosí. Amador Cárdenas convino en arrendar La Flor de Jimulco por diez años, obteniendo a cambio el $6 \%$ sobre las utilidades líquidas que anualmente llegara a obtener Adolfo Marx.

En los contratos de compraventa establecidos por la Explotadora de Caucho, ésta se reservó el derecho de in.

${ }^{8}$ Ibid., vol. 12,1909 , insc. 56 y 57. tervenir directamente en los campos productores, introducir animales de tiro y carros para el traslado del arbusto, así como instalar campamentos y utilizar agua y leña para consumo de su gente.

El 21 de mayo de 1906 se formó una nueva Sociedad Mercantil Anónima denominada Compañía Guayulera de Torreón, S. A., a la que uno de los socios, José Ángel Dávila, le traspasó "ciertos derechos", conferidos a su vez por el general Francisco Naranjo, entre ellos la venta del guayule existente en los 281 sitios de ganado mayor que poseía. ${ }^{9}$ Naranjo era uno de los prominentes militares cercanos a Díaz. Había participado en las guerras de Reforma e Intervención y secundó los planes de La Noria y de Tuxtepec. Su labor como ministro de Guerra y Marina durante la presidencia de Manuel González, y luego como director del Ferrocarril Nacional Mexicano, le valieron gozar de una serie de prerrogativas que manejó de la manera más conveniente.

La más importante compañía gua. yulera de capital estadunidense que se estableció en México, fue la Continental Mexican Rubber Company. El periódico duranguense La Evolución reseñó:

La Continental [...] a cuyo frente se encuentra el hijo del rey de los monopolizadores, John D. Rockefeller, acaba de comprar las fábricas de guayule establecidas en Gómez Palacio y en Torreón,

\footnotetext{
${ }^{9}$ Ibid., vol. 8, 1905, insc. 94. El Consejo de Administración estaba formado por el licenciado Manuel Garza Aldape, Francisco A. Villanueva, Miguel Robledo, José Ángel Dávila y Baltazar Peña.
} 
dando por ellas y por la gran existencia de guayule que tienen, la enorme cantidad de 4000000 de pesos [...] Rockefeller, que es el hombre más rico del mundo debido al monopolio del petróleo, se propone monopolizar también la goma y el guayule. ${ }^{10}$

Efectivamente, John D. Rockefeller Jr., Daniel Guggenheim y Edward B. Aldrich estaban asociados en la Intercontinental Rubber Company, ${ }^{11}$ la cual controlaba una serie de subsidiarias: ${ }^{12}$ Agricultural Products Corporation en Arizona; American Congo Company en el Congo Belga; Compañía Ganadera y Textil de Cedros, S. A. en Zacatecas; Continental Mexican Rubber Company en Torreón, Coah.; ${ }^{13}$ Continental Rubber Company of New York, y Rubber Exploration Company. ${ }^{14}$ Los socios de estas empresas eran personas económicamente muy poderosas y vinculadas a grandes negocios o a la política estadunidense. Rockefeller junior era el heredero del fundador del emporio petrolero de la Standard Oil, cuyos intereses en otras muchas empresas -comercio, minería, banca, etc.lo convirtieron en "el primer billonario" de Estados Unidos y, probablemente,

\footnotetext{
${ }^{10}$ La Evolución, 12 de octubre de 1906, Durango.

${ }^{11} \mathrm{La}$ Intercontinental fue organizada en 1906 , al tiempo que las fuentes de hule natural en Sudamérica y Sudáfrica comezaron a escasear considerablemente y de que fue descubierto el guayule en México.

${ }^{12}$ Supplement, 1919.

${ }^{13} \mathrm{RP}$, Registro público del comercio del distrito de Viesca, 1910, vol. 13, insc. 28.

${ }^{14}$ En 1917 se sumó la Continental Plantation Company, con intereses en Sumatra, etcétera.
}

del mundo. ${ }^{15}$ Daniel, por su parte, era el segundo hijo de Meyer Guggenheim, ${ }^{16}$ comerciante de origen suizo radicado en Estados Unidos, quien llegó a ser uno de los hombres más representativos del imperialismo industrial estadunidense. Los Guggenheim invirtieron sus capitales en la minería mexicana, creando en la república una extensa red empresarial que incluyó fundiciones, minas, molinos de metal y refinadoras, influyendo significativamente en la vida económica del país.

Daniel era el negociador de las empresas familiares y responsable de la reorganización de la American Smelting and Refining Company que desde 1901 quedó bajo su control. Al morir su padre, continuó siendo el estratega de los negocios, e inició la explotación de minas de estaño, oro, cobre, diamantes y plantaciones de hule en sitios tan diversos como Alaska, Bolivia, Congo Belga y la Angola Portuguesa. ${ }^{17}$

Edward B. Aldrich, por su parte, era hijo de Nelson Wilmarth Aldrich, reconocido político con una larga trayectoria en el Senado estadunidense, poseedor de grandes intereses económicos

${ }^{15}$ Como lo afirman Collier y Horowitz, Rockefeller, 1987, p. 14.

${ }^{16}$ Los hermanos Guggenheim eran: Isaac, Daniel, Murry, Salomón, Benjamín, Simón y William.

${ }^{17} \mathrm{El}$ descubrimiento de las posibilidades industriales del guayule no se restringieron a América. El rey Leopoldo de Bélgica buscó allegarse fuentes de abastecimiento cauchífero y, pära tal fin, contrató con la Guggenheim Iixploration (GUGGENEX) investigar el potencial de dicha planta en el Congo. Daniel Guggenheim fue el encargado de establecer los contactos y, tanto en México como en África, se anotó espectaculares triunfos. 


\section{SECUENCIG}

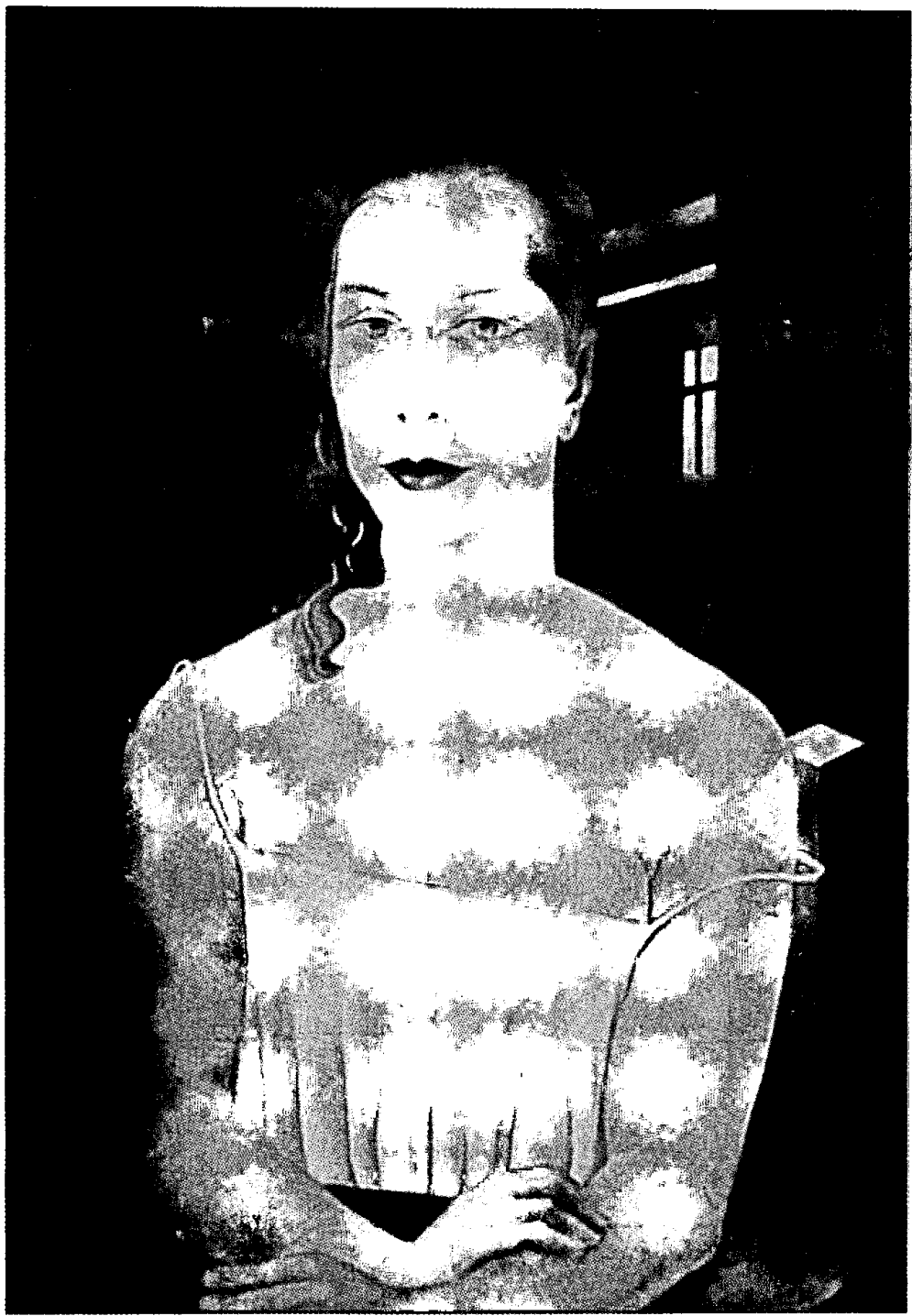


en la banca, el azúcar, el hule etc. Cercano al presidente Theodore Roosevelt, su mayor contribución política estuvo en el campo de la reforma bancaria y como presidente de la Comisión Monetaria Nacional. Nelson W. Aldrich era suegro de Rockefeller junior, y Edward, su cuñado. Los tres socios, Rockefeller, Guggenheim y Aldrich, representaban dinero, influencia y poder en niveles fuera de toda competencia en países como México.

Dada la envergadura de la Continental, ésta gozó de grandes ventajas otorgadas por el gobierno de Díaz. Correspondió a William $H$. Stayton, representante de la compañía en México, ser el encargado de comprar toda clase de bienes muebles y raíces, adquirir contratos, derechos, acciones, bonos y otras obligaciones de compañías anónimas, sociedades mercantiles o de individuos en cualquier parte de la república. Pagaba grandes sumas por el usufructo de las tierras, particularmente por aquellas cercanas a las vías férreas, con el fin de disminuir los costos de transportación y eliminar la competencia. Además, buscó asegurarse, en exclusiva, todas las patentes para el procesamiento del guayule. El comportamiento de la Continental Mexican Rubber Company siguió en nuestro país un patrón semejante al de la Standard Oil, pues logró manipular el acaparamiento del guayule mediante la captación de empresas competidoras.

La fábrica que Continental Mexican Rubber Co. construyó en Torreón, tenía capacidad para procesar 1000000 de libras de hule al mes y contaba con oficinas administrativas, un hotel y casas para los empleados. Mediante un tratamiento mecánico del arbusto, éste producía un $10 \%$ de caucho que luego era mezclado con el hule conocido como "pará" de Brasil, haciéndolo alta. mente resistente.

A fines de 1906 se constituyó otra empresa más, La Guayulera, S. A. ${ }^{18}$ con el objetivo principal, al igual que sus predecesoras, de adquirir por compra, arrendamiento o cualquier otra forma de contrato, propiedades productoras de guayule, palma, lechuguilla y sotol.

En enero de 1907 se estableció en México The Mexican Crude Rubber Co. ${ }^{19}$ con el propósito de fabricar, comprar y vender hule crudo. La empresa se convirtió en una de las competidoras estadunidenses más cercanas de la Continental.

En 1908, una nueva empresa hulera inició sus operaciones en México, la United States Rubber Company que, con capital inicial de 5000 pesos y una duración de 50 años, se proponía explotar todo lo relacionado con la industria del caucho. Esta compañía tuvo ciertos acuerdos de orden econónuico con Intercontinental Rubber Company, sin embargo, mantuvo su autonomía.

18 RPP, Registro público del comercio, 1906, vol. 9, insc. 23. La Guayulera S. A., era una sociedad mercantil familiar integrada por el licenciado Manuel Garza Aldape (presidente), director Salomé Garza Aldape (comisario) y Rafael Aldape Quiroz (secretario y tesorero).

${ }^{19}$ Ibid., insc. 36. The Mexican Crude Rubber Company estaba constituida y autorizada con arreglo a las leyes del estado de Michigan, Estados Unidos de Norteamérica. Su consejo de administración estaba integrado por Ralph $M$ Dyar (presidente), W. F. MC.Graw, W. E. Parker y H. B. Bennet (secretario) y encargado de los negocios en México. 
El 4 de noviembre de 1910 se constituyó la Compañía Hulera de Monclova, S. A., con un capital de 50000 pesos para explotar la fábrica denominada El Puerto del Carmen, establecida en el municipio de Monclova. Enrico Notholt, Carlos Perry y Rodolfo Nickler, socios y accionistas únicos, formaron el consejo de administración.

Las más importantes corporaciones extranjeras llegaron para, en ocasiones, contender $o$ asociarse con capitalistas mexicanos, sin embargo, existieron también empresarios con capitales menores que quedaron en desventaja frente a aquellas poderosas compañías.

Entre los competidores nacionales sobresalió la familia Madero, que ingresó al mercado del guayule casi por accidente al adquirir en Coahuila, a muy bajo precio, grandes porciones de terrenos desérticos cubiertos del arbusto. Cuando llegó la Continental, los Madero ya contaban con un mercado seguro para su hule, el cual era procesado en las fábricas Explotadora Coahuilense, S. A., Guayulera Nacional, Australia, S. A. y Salvador Madero y Co., Sociedad en Comandita. Tan sólo la Explotadora Coahuilense, ubicada en Parras, cuyos productos eran exportados a Alemania, obtuvo en un año más de un millón de pesos en ganancias.

Sin embargo, los Madero no sólo obtenían materia prima cosechada en sus propiedades; para completar el abastecimiento tenían arrendadas tierras en los partidos de San Juan de Guadalupe, Mapimí y Cuencamé, Dgo., topándose frecuentemente con la desleal competencia de la poderosa Continental que, extramuros de Coahuila y durante la primera etapa de la revolu- ción, pudo aprovecharse de la situación anómala y de desorden, asestando un duro golpe al abastecimiento legal tanto de los Madero como de otros inversionistas nacionales.

El contexto regional en que se desarrolló la explotación agrícola guayulera y su orientación hacia el mercado foráneo estuvo condicionado por un marco natural que dividió a la economía entre intereses nacionales y extranjeros, la mayoría de las veces difícilmente conciliables.

\section{EFECTOS Sociales de La ECONOMÍa GUAYULERA}

¿Qué consecuencias trajo al agro mexicano el florecimiento del guayule? En primer lugar, propició un incremento en el valor de la tierra considerada como de "bajo rendimiento". En segundo lugar, se convirtió en una fuente alternativa de ingresos a muy distintos niveles. En el norte de México, su auge coincidió con la crisis del campo y la minería. La falta de lluvias durante el periodo de sequía no incidió en esta planta tan dramáticamente como ocurrió con el algodón o los productos alimenticios y, en tercer lugar, alentó pleitos entre particulares, compañías y pueblos, reavivando viejos litigios agrarios.

En los partidos de Durango, hacendados y/o empresarios intentaron asegurarse la producción de guayule controlando el mayor número de terrenos por compra, arrendamiento o despojo. Sin embargo, hay que agregar a gente que comenzó a vivir del hurto y de las ventas ilegales. El guayule abarcó y 
afectó la esfera de la vida económica, política y social de Durango, Coahuila, Zacatecas, San Luis Potosí, Chihuahua y Nuevo León, y puso en evidencia la competencia por alcanzar el abastecimiento del mercado exterior.

El desarrollo de la industria guayulera contribuyó de manera esencial a la prosperidad de La Laguna, ya que desde el inicio de su industrialización los precios de la planta fueron en aumento, con excepción de la época correspondiente al periodo más difícil de la crisis económica en 1908, que sufrió una fuerte baja; sin embargo, el guayule fue, entre los productos agrícolas, el que primero se recuperó y aumentó su valor convirtiéndose en poco tiempo, muy por encima del algodón, en el principal producto de exportación (véase gráfica 2).

Ahora bien, la sobreexplotación del arbusto cauchífero llegó a tales niveles que, según Carlos Patoni, en 1910 la planta estaba casi agotada, con el agravante de que no podía reproducirse a la misma velocidad con que se consumía. La aterradora perspectiva de acabar con la materia prima abrió el campo a la investigación y experimentación de métodos para su cultivo. William Meyers afirmó que el crecimiento y la maduración del arbusto tomaba 50 años, cuando en realidad se requieren cinco. ${ }^{20}$ Patoni escribió:

[...] la planta está casi agotada; queda muy poca en el estado de Durango; en el de Coahuila hay quizá algo más, pero siempre en cantidad limitada, y lo mismo pasa en Zacatecas, donde apenas

${ }^{20}$ Meyers, Forja, 1996, p. 200. hay una o dos haciendas que conservan su guayule [...]. Quizá dentro de un año se habrán paralizado ya muchas fábricas [...] por falta de materia prima. Pasarán después dos o tres años más, antes de que lleguen a un desarrollo conveniente -para ser cortadas- las plantas que han dejado de arrancarse por demasiado pequeñas $[. .$.$] , pero como esa canti-$ dad de guayule $[. .$.$] es muy limitada,$ apenas podrá alimentar algunas de las fábricas que hoy existen durante uno o dos años más. Así es que, dentro de unos cinco años, la industria de la extracción del caucho del guayule habrá acabado definitivamente si no se busca, desde luego, un medio de reproducir y propagar la planta $[\ldots]^{21}$

La falta de reproducción del guayule tenía que ver con las estipulaciones de los contratos; los compradores pedían que la planta fuera arrancada de raíz en lugar de cortada, ya que, proporcionalmente, la parte subterránea del tallo era la que contenía más caucho; pero sin duda se trataba de un recurso que aceleraba la operación de los recolectores y que disminuía significativamente los costos, sin prever los desastrosos resultados que ello ocasionaría. Para no ver desaparecida la industria, comenzaron a practicarse diversos sistemas de cultivo; Patoni, por ejemplo, ensayó sembrar pequeñas cantidades de semilla de guayule en su jardín y observó que la planta, regada escasamente, nacía bien. ${ }^{22}$ Los estu-

${ }^{21}$ Carlos Patoni, "Algunos datos sobre el guayule. Urgencias de su cultivo", Perídico Oficial del Gobierno del Estado de Durango, 27 de febrero de 1910.

22 Observó que las plantas nacidas en 1906 , para 1910 alcanzaban una altura de 60 o más 


\section{SECUENCIA}

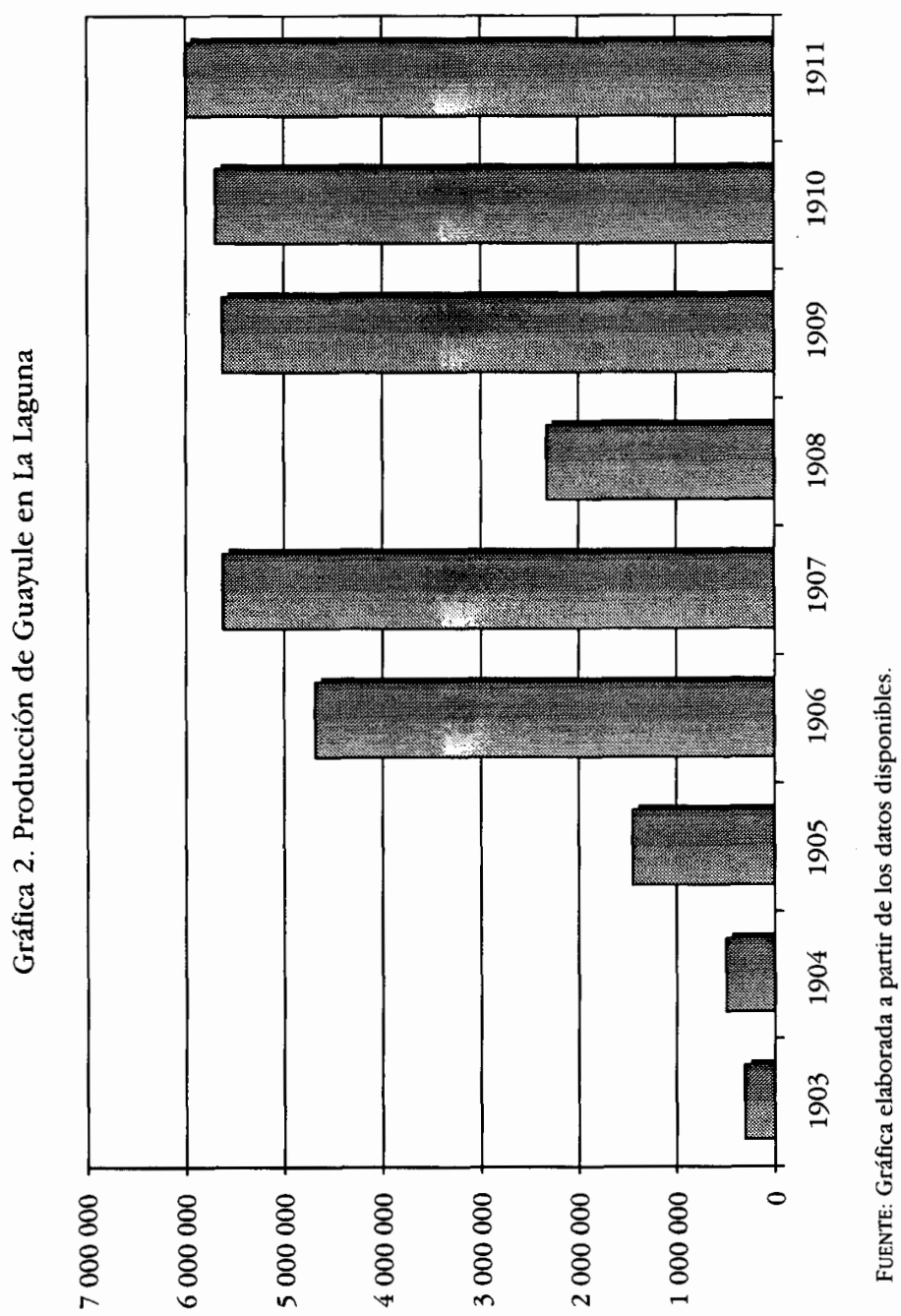


dios de Patoni estaban encaminados, por un lado, a mejorar e incrementar su cultivo y, por otro, a sustituir con dicho producto el de las tierras algodoneras de baja productividad. Sus investigaciones lo llevaron a realizar una interesante comparación entre el rendimiento de ambos productos: señaló que las mejores tierras de La Laguna podían producir por lote, en años propicios - por cierto poco frecuentes- entre 1000 y 1200 quintales de algodón. Aunque regularmente solían obtenerse, en promedio, 800 quintales, es decir ocho por ha, que al precio de 25 pesos el quintal suponían 20000 pesos por hectárea.

El cultivo algodonero exigía muchos brazos -dependientes, mayordomos de campo, etc. $-y$ por tanto fuertes erogaciones de dinero. A los pizcadores se les pagaban cuatro pesos por quintal y, en ocasiones, seis pesos o más en las mejores tierras. Por el despepite y empaque se le adicionaban dos pesos dejando, al final, una utilidad neta de 100 pesos por hectárea contra 125 pesos de la de guayule. La diferencia, decía Patoni, correspondía al interés que generaba el dinero en los cinco años que tardaba el guayule en poder ser cosechado. Patoni determinó que la planta podía producir una utilidad igual a la del algodón en buenas tierras, sin embargo, tomando en cuenta que con una misma can-

centímetros, con un peso aproximado de 350 gr, y el tallo de entre 13 a $14 \mathrm{~mm}$ de diámetro en la base que, de ese modo, pasaban ya del grueso fijado en los contratos de guayule. Finalmente, determinó que las plantas que llegaran a pesar entre 400 y 500 gr darian un producto de $6000 \mathrm{~kg}$ por hectárea. tidad de agua podía cultivarse una extensión cuatro o cinco veces mayor de guayule, la diferencia a favor de éste resultaba enorme. Con la ventaja adicional de que la falta de agua durante uno o más años no comprometía el resultado final de la cosecha, puesto que no requería condiciones climáticas especiales y podía soportar temperaturas muy altas sin secarse, y muy bajas sin helarse. Es claro que Patoni no pretendió sustituir la siembra en las parcelas aptas para la fibra blanca, sólo propuso que los terrenos con bajo rendimiento algodonero, inmediatos a las sierras -de peor calidad por su alto contenido de cal- fueran mejor aprovechados cultivándolos con guayule.

El temor de que el guayule acabara por desaparecer, propició que un grupo de botánicos estadunidenses buscara formas de producción: William $\mathrm{H}$. Bray y A. Newman, de la Universidad de Texas en El Paso, fueron los encargados de recorrer el norte de nuestro país recogiendo muestras de semillas para experimentar su cultivo en aquel estado. Mientras que otro grupo visitó las más importantes haciendas guayuleras en Durango y Coahuila, tal y como lo reseñó un diario de Torreón. ${ }^{23}$

La hacienda de Cedros, localizada en el estado de Zacatecas, fue a principios de siglo uno de los mayores latifundios norteños, con algo más de tres cuartos de millón de hectáreas. Era propiedad de los señores Zertuche y Fuertes, quienes mantuvieron un prolongado litigio agrario con gente del partido de San Juan de Guadalupe,

23 "El oro vegetal", El Nuevo Mundo, 28 de mayo de 1907, Torreón, Coah. 
Dgo., alegando ser los dueños de ciertos terrenos guayuleros que, afirmaban, estaban incluidos en la composición celebrada con la Secretaría de Fomento. ${ }^{24}$ El litigio no prosperó y el asunto judicial permaneció estacionario, sin que la gente volviera a ser molestada.

A partir de que la hacienda pasó al dominio de la Compañía Ganadera y Textil de Cedros, sus representantes y accionistas, Práxedis de la Peña y Alberto Lazalde, reiniciaron la demanda involucrando en ella al Ayuntamiento de la municipalidad, porque una parte de la tierra disputada estaba comprendida dentro de los ejidos de San Juan. Los nuevos propietarios alegaban haber adquirido la citada finca con todos sus anexos, entre los que se incluían, según ellos, los adjudicados por la Secretaría de Fomento a Zertuche y Fuertes, ubicados entre la línea de transacción y los linderos de los estados de Zacatecas y Durango.

Los cuantiosos intereses económicos en juego llevaron al apoderado de la compañía a solicitar el apoyo del gobernador de Durango, quien a su vez giró órdenes al jefe político de San Juan para que, apoyado por fuerzas armadas, suspendiera el corte del gua-

\footnotetext{
${ }^{24}$ Se llamaba composición de tierras, al medio de adquirir terrenos baldíos con uno de dos objetos: uno, que la Secretaría de Fomento declarara que en el terreno que poseía el solicitante en plena y perfecta propiedad no había demasías, excedencias ni baldíos de ningún género; dos, con objeto de que las demasías, excedencias y baldíos que alguno poseyera con justo título por espacio de 20 años o más, le fueran adjudicados en propiedad por el gobierno. Véase Orozco, Legislación, 1895, t. 1, p. 417.
}

yule. La orden de Esteban Fernández implicó la aceptación del gobierno duranguense de que los terrenos situados al oriente de los ejidos eran de la propiedad de Cedros; con ello se pretendió resolver arbitrariamente y de facto el litigio agrario, ignorando la competencia de las autoridades judiciales.

La cuestión, sin embargo, distaba mucho de haberse resuelto en forma tan ilegal, antes bien se complicó, puesto que en aquellos terrenos existían varios ranchos y pequeñas congregaciones que fundaban sus respectivos derechos de posesión y propiedad en una tenencia pública, pacífica, continua, con aprovechamiento integral de las tierras de labor: cultivos, agostaderos y productos naturales como leña, carbón, lechuguilla y principalmente guayule, que en distintas épocas habian cortado y vendido. ${ }^{25}$ Con el apoyo de las autoridades durangueñas, Enrique Alcalá, apoderado de Cedros, obtuvo una orden para que los jefes de cuartel aprehendieran a la gente que cortaba guayule sin autorización de la Compañía.

$\mathrm{Al}$ ejercer funciones que no le competían, Fernández fue acusado de violar las garantías constitucionales. Era un hecho evidente que, en Durango, el poder ejecutivo se había robustecido a expensas de los otros poderes tendiendo a traspasar los límites que la ley le

${ }^{25}$ Archivo Histórico del Gobierno del Estado de Durango (en adelante AHGED), Juzgado de Distrito, juicio de amparo iniciado el 6 de junio de 1907. Sentencia, 12 de agosto de 1907, solución: amparo archivado el 16 de diciembre de 1908. 
imponía. Los actos de aquél invadían frecuentemente el dominio judicial, dejando sentir su perniciosa influencia y ocasionando graves daños y perjuicios. Contra esa invasión de funciones y actos atentatorios, los afectados recurrieron invariablemente al recurso del amparo, considerado como "el valladar de todos los abusos [...] la fuerza que regula las funciones de los órganos políticos y que restablece el equilibrio interrumpido". ${ }^{26}$

El licenciado Ignacio Borrego, apoderado de los propietarios de San Juan de Guadalupe, señaló que sus representados se encontraban en posesión de los terrenos comprendidos en una realidad geográfica perfectamente definida y cuyo dominio estaba debida y legalmente comprobado.

Como se ha dicho, el carácter litigioso del asunto radicaba en que ambas partes alegaban derechos de propiedad: la Compañía Ganadera y Textil de Cedros fundaba su acción de dominio en títulos de compraventa y composición establecidos con la Secretaría de Fomento; por su parte, los pobladores de San Juan de Guadalupe lo hacían basados en la prescripción adquisitiva e invocando dos artículos de la Ley Civil que, en síntesis, expresaban lo siguiente: art. 819, para efectos legales, la posesión da, al que la tiene, presunción de propietario, y art. 825, se concede al poseedor de buena fe los frutos percibidos. ${ }^{27}$

${ }^{26}$ AHGED, Opinión del licenciado Ignacio Borrego sobre los excesos de autoridad del ejecutivo. Acervo sin clasificar, 1907.

${ }^{27}$ Ibid.
En vista de que las autoridades estatales -el gobernador, el jefe político e incluso el juez-sancionaron el despojo efectuado por la poderosa Compañía Ganadera y Textil de Cedros, sin haber dado oportunidad a la gente de ser oída o vencida en juicio, los afectados recurrieron a la Suprema Corte de Justicia que, por laudo de 30 de noviembre de 1908 , falló en su favor.

En el fondo de todo este largo proceso se hallaba el hecho de que la Compañía Ganadera y Textil de Cedros estaba integrada por un grupo de inversionistas que aglutinaba a las siguientes empresas: Continental Mexican Rubber Company, socia y accionista mayoritaria; Compañía Coahuilense, S. A., y Compañía Explotadora de Guayule, S. A., ambas propiedad de Práxedis de la Peña y socios, y Compañía Explotadora de Hule, S. A. (de los hermanos Pimentel y Fagoaga), ${ }^{28}$ entre otras que, como ya se mencionó, deseaban controlar el mayor número de terrenos productores de hule, al tiempo que buscaban contrarrestar la competencia de la Compañía Explotadora de Caucho Mexicano que había conseguido firmar contratos justamente con Felipe Rodríguez, propietario de la hacienda de Milpillas con sus anexos El Capadero, El Zacate, La Granja y Los Sauces, así como con los ejidos de Orégano, Santo Niño y Agua Nueva, incluidos en el litigio agrario. La expansión lograda por la Compañía Explotadora hacía temer a la Continental un menoscabo en su disposición de materia

\footnotetext{
${ }^{28}$ RPP, Registro público del comercio, 1909 , vol. 12 , insc. 54 .
} 
prima, pues aquélla parecía aventajarle en un dilatado ámbito: poseía derechos otorgados por la Secretaría de Fomento para explotar el caucho existente en terrenos nacionales de los distritos Jiménez, Camargo e Iturbide en el estado de Chihuahua; contratos para aprovechar el guayule de Carlos Sánchez Navarro, en Ramos Arizpe y Saltillo, Coahuila; el de las haciendas Ciénega de Rocamontes y Guadalupe Garcerón en Concepción del Oro, partido de Mazapil, Zacatecas, y el de la hacienda de Santa Rita en el estado de Nuevo León. Esto da una idea del significado económico del arbusto, de los negocios y de la competencia entre aquellas poderosas compañías por ganar el abasto de un producto amenazado de extinción.

Además de los pleitos agrarios en que se vio involucrada la Continental, también tuvo que afrontar otro tipo de problemas judiciales, como demandas por uso indebido de patentes de privilegio para el beneficio del guayule. ${ }^{29}$ La avidez empresarial por ganar a toda costa la materia prima, le granjeó severas críticas por la depredación del medio ambiente y sus efectos negativos sobre la salud. Fue bien conocido el hecho de que, como resultado de las descargas residuales que contaminaron el agua en Jimulco, la Compañía Explotadora de Caucho Mexicano provocó una epidemia de tifo. Correspondió al doctor Leopoldo Escobar informar sobre la situación sanitaria del lugar, señalando que los miasmas que despedía el desagüe de la fábrica habían

\footnotetext{
${ }^{29}$ Archivo Histórico de la Secretaría de Relaciones Exteriores (en adelante AHSRE), sección 8, caja 29, exp. 30, 2 de septiembre de 1909.
}

sido la causa de que varias personas enfermaran de fiebre. Las autoridades ordenaron cegar los depósitos como remedio para evitar que se extendiera el mal. ${ }^{30}$ Estas noticias, aunque publicadas tímidamente en los diarios laguneros, pusieron al descubierto el impacto que a nivel regional provocó la economía guayulera y los dramáticos cambios que trajo consigo.

\section{CUENCAMÉ, UNA REGIÓN GUAYULERA DE DURANGo}

En Cuencamé, partido localizado al este de Durango, existieron algunos de los más espectaculares latifundios de la entidad, entre los que destacaron: Juan Pérez y Santa Catalina del Álamo, que reunían el $54.4 \%$ del valor rústico de todo el partido.

En Cuencamé, varias propiedades compartían una circunstancia común, litigios agrarios con comunidades vecinas: la hacienda de Juan Pérez, propiedad de la familia Moncada; Santa Catalina, de los Martínez del Río; Sombreretillos de Campa, de los López Negrete; Atotonilco, de los González Saravia; Melilla de los hermanos Pimentel y Fagoaga. Todos ellos mantuvieron, en diversas épocas, acres disputas y largos juicios sobre linderos y posesión de terrenos con pueblos aledaños que derivaron en hostigamientos, amagos o agresiones directas.

La hacienda de Juan Pérez tenía una extensión de 288000 hectáreas y era propiedad de Antonio Moncada, quien

${ }^{30}$ Nuevo Mundo, 8 de mayo de 1907 , Torreón, Coah. 
la heredó de los condes de San Mateo de Valparaíso o del Jaral. Sus terrenos se extendían desde el pueblo de San Juan del Río, abarcando los llanos de Tapona, en el municipio de Peñón Blanco, hasta los linderos con el estado de Coahuila en el río Aguanaval, en una franja de $180 \mathrm{~km}$ de longitud. Sus anexos más importantes eran Tapona y Mazamitote. El primero de éstos poseía las mejores tierras de cultivo temporalero, y algunos terrenos recibían el beneficio del río del Peñón, siendo uno de los centros productores de maíz y frijol más importantes del estado.

Pablo Martínez del Río compró Santa Catalina del Álamo en 1897 e invirtió en ella más de 50000 pesos en el mejoramiento de la presa de Las Mercedes y en la red de canales y zanjas para irrigar los campos de trigo y algodón; pozos y molinos movidos por agua; ganado pura sangre, $16000 \mathrm{ca}-$ bezas de caballos y mulas, y 100000 cabezas de ganado menor, cabras y ovejas para la producción de carne y lana. Introdujo maquinaria para trillar el trigo y despepitar algodón. El nuevo propietario explotó su cercanía con Porfirio Díaz y utilizó su preeminencia como abogado corporativo para cultivar relaciones con políticos poderosos en Durango, entre los que destacaron los gobernadores Juan Manuel Flores y Esteban Fernández.

El latifundio -Santa Catalina del Álamo y Anexas-alcanzó 418193 hectáreas que se extendían a través del partido de Cuencamé y de los vecinos Nazas y San Juan del Río. Para fines administrativos, la propiedad estaba dividida en seis secciones: Santa Catalina, Álamo, Covadonga, Mercedes, Guada- lupe y Cruces, y Pasaje. Esta última con pródiga dotación de guayule. ${ }^{31}$

Atotonilco de Campa fue adquirida mancomunadamente, en 1875 , por el prominente abogado duranguense Ladislao López Negrete, diputado en el Congreso estatal y consultor privado del gobierno, y por el político y hacendado Buenaventura González Saravia, quienes se dedicaron a la cría de ganado y a la producción de maíz y frijol. Con las tierras, López y Saravia adquirieron los problemas y litigios que, desde 1843 , seguía el vecindario de Cuencamé por linderos.

En 1890, los socios decidieron dividir la hacienda en dos fracciones, una al sur y otra al norte, la primera de las cuales quedó en propiedad de González Saravia y la segunda de López Negrete, acordando que cada cual defendería los terrenos que estuvieran usurpando los vecinos de Cuencamé y Ocuila dentro de sus linderos. Tras la muerte de Ladislao, ocurrida en 1897, la propiedad pasó a manos de su viuda, quien a su vez la rentó a sus hijos, Laureano y Ángel, que bajo la razón social López Negrete Hermanos se hicieron cargo de su explotación comercial.

El latifundio estaba integrado por Sombreretillos -donde estaba la casa principal y la administración- y sus anexos: ranchos de San José, Cerrito Colorado, Carleña, Cadillo, El Jagüey, La Cuchilla y Las Crucecitas, así como las tierras que alegaban habían sido "usurpadas" por los vecinos de Cuencamé -El Ojito, Las Cuevas, Cerro Blanco, El Pepino, Ojo Seco, La Joya, La Joya de Arriba, El Conejo, La Gatuña

\footnotetext{
${ }^{31}$ Walker, "Homegrown", 1992, pp. 242-245.
} 
y rancho de don Miguel. ${ }^{32}$ La superficie total de la propiedad comprendía 83700 hectáreas, constituida mayoritariamente por terrenos de agostadero. En principio, la actividad fundamental de la hacienda estuvo dirigida a la crianza y engorda de ganado caprino y ovino, a la producción de mezcal, maíz y frijol, y al aprovechamiento de diversos productos naturales, entre ellos el guayule. ${ }^{33}$

No sabemos con exactitud la fecha en que los hermanos Pimentel y Fagoaga adquirieron en propiedad la hacienda de Melilla y anexas, cuyos terrenos comprendían el municipio de Santa Clara, partido de Cuencamé, y San Juan de Guadalupe, Dgo. Los litigios en los que se vieron involucrados aquéllos tuvieron que ver con los vecinos de Santa Clara y los Moncada, dueños de Juan Pérez. Los primeros compraron diversas fracciones de los terrenos de la hacienda y los segundos llegaron a un arreglo de límites de común acuerdo. ${ }^{34}$

Fernando y Jacinto eran hijos de Francisco Pimentel, conde de Heras, y Josefa María Gómez Fagoaga, hija del marqués del Apartado. Fernando casó en primeras nupcias con María Bracho, perteneciente a una de las más prominentes familias de la elite duranguense. La alta posición social de que gozaron ambos hermanos les permitió desa-

\footnotetext{
${ }^{32}$ Memorándum enviado por el licenciado Francisco O'Reilly a Porfirio Díaz, 12 de mayo de 1910, Archivo Porfirio Díaz (APD), leg. xxxv, doc. 008742. En el documento se incluye al rancho La Cuchilla.

${ }^{33}$ Villa, "Este", 1998, pp. 6-8.

${ }^{34}$ Catálogo, 1985, vol. 1, pp. 330-331, 370371.
}

rrollar los más variados negocios y cargos políticos. Banqueros, comerciantes y agricultores, Pimentel Hermanos lograron extender su radio de acción en un dilatado territorio que abarcó los estados de Durango, Coahuila, Zacatecas, Guanajuato, Michoacán, Estado de México, Puebla y ciudad de México. ${ }^{35}$ Gracias a su disposición de capitales, pudieron asociarse ventajosamente con la Continental Mexican Rubber Company en el negocio del guayule, prin. cipal producto agrícola de Melilla.

El partido de Cuencamé concentró uno de los mayores índices del valor agrario en la entidad, produciendo $10.40 \%$ del total estatal de maiz, $8.19 \%$ de frijol y $21.45 \%$ de trigo. La ganadería era además una actividad fundamental en la que destacaban Santa Catalina, Atotonilco y Sombreretillos de Campa. Los informes gubernamentales manifiestan, de manera general, cuáles eran los cultivos principales de las haciendas durangueñas, sin embargo, no debemos perder de vista que la información es incompleta, ya que el número de hectáreas sólo nos da idea de la magnitud de las propiedades, pero no de la calidad de las tierras que, aun siendo parte integral de un mismo predio, guardaban enormes diferencias entre sí. ${ }^{36}$

Por otro lado, no todas las propiedades de Cuencamé están mencionadas en las memorias de gobierno y tampoco, de manera especial, los productos agrícolas naturales que se aprovechaban. Cuando el guayule probó ser un producto redituable, se comenzó a

\footnotetext{
${ }^{35}$ Vidal y Flores, Fernando, 1907.

${ }^{36}$ Memoria, 1906.
} 
censar, como aparece en el informe de 1908-1910, en el que se incluye la producción anual de las haciendas ${ }^{37}$ (véase cuadro 1); sin embargo, a pesar de que existían otros predios que lo explotaban, sólo se hace referencia a Juan Pérez, Sombreretillos de Campa, Sombreretillos de Jimulco y Pasaje -anexo de Santa Catalina.

El boom guayulero hacía suponer una gran existencia de materia prima para el mercado exterior, lo cual se corroboraba con la proliferación de contratistas que buscaban asegurar el abastecimiento de las empresas que representaban. Esa inusitada demanda en zonas castigadas por la naturaleza, propició que se incrementaran las disputas por la tenencia y el usufructo de la tierra.

En 1905, por ejemplo, la Sociedad Agrícola López Negrete Hermanos, arrendataria de Sombreretillos de Campa, firmó varios contratos con la Compañía Explotadora de Hule, S. A., mediante los cuales se obligó a vender todo el guayule producido en la hacienda y sus anexos; a garantizar -por diez añosaguajes y agostaderos en beneficio de las bestias de tiro y carga destinadas a transportar la goma; a otorgar derecho de paso por sus terrenos a personal de la empresa y a conseguir que a la "Explotadora de Hule no se le impusieran contribuciones onerosas y se le impartiera toda la protección posible". ${ }^{38}$ Para poder garantizar el cum.

${ }^{37}$ Memoria, 1910, anexo 82.

${ }^{38}$ Instituto Estatal de Documentación, Saltillo-Archivo de Notarías del Estado de Coahuila (IEDS-ANEC), protocolo del notario Guillermo Espejo, 12 de enero de 1910. plimiento de los compromisos adquiridos, los López Negrete mandaron construir un cerco en los linderos de su hacienda con la población de Ocuila, a la que disputaba la propiedad de unos terrenos, hecho que empeoró las tensiones entre ambas partes.

Mientras hacendados y vecinos intentaban dirimir sus diferencias, la Explotadora de Hule se asoció con la Continental Mexican Rubber Company. Fue entonces que López Negrete Hermanos mediante nuevo contrato -1 de junio de 1909 a 20 de junio de 1915-, permitió que sólo ésta cortara todo el guayule de la finca. Es decir, al igual que su antecesora, la Continental aseguró el libre acceso a la hacienda adquiriendo con ello los mismos derechos que había poseído su socia.

Los problemas agrarios entre la hacienda de Sombreretillos y la gente de Ocuila no tuvieron que ver, en sus origenes, con la explotación del guayule, sin embargo, fue un aspecto que acabó por fundirse en sus demandas. En situación análoga quedaron los vecinos de las haciendas de Santa Catalina del Álamo y Juan Pérez, gente que mayoritariamente no tenía acceso a tierras agrícolas irrigadas. Las labores temporaleras jugaban malas pasadas a los agricultores, y los años malos solían ser más frecuentes que los buenos. De allí que el guayule se convirtiera en una alternativa como fuente de ingresos, por ser altamente resistente a los vaivenes de la naturaleza.

Los negocios productivos, sin embargo, estaban reservados a la gente que reunía tres condiciones: tierra, capital y contactos. Los López Negrete, por ejemplo, a pesar de haberse com- 


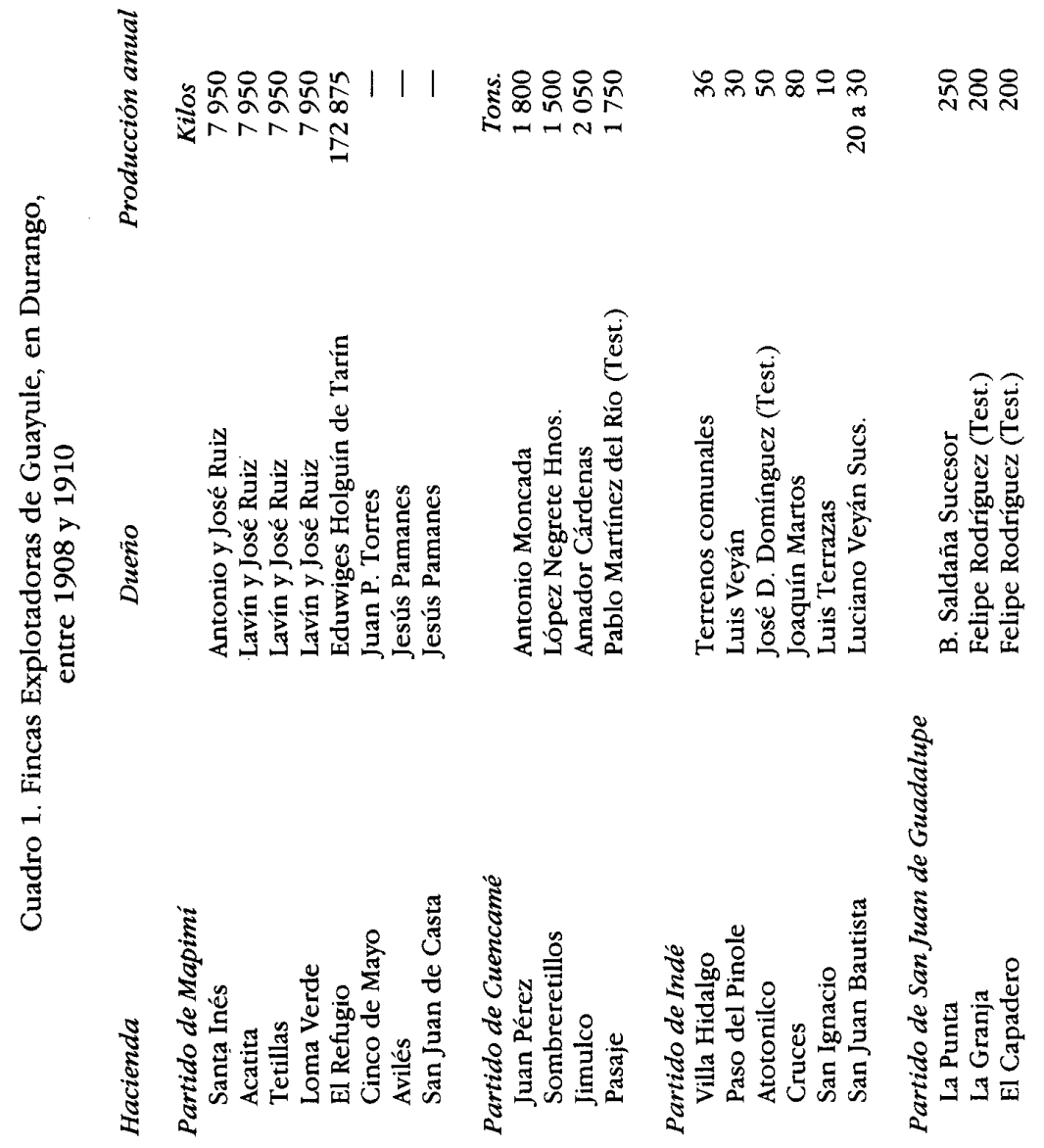




\section{SECUENCIA}

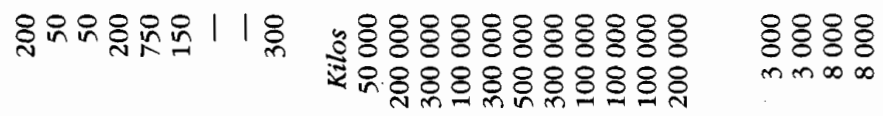
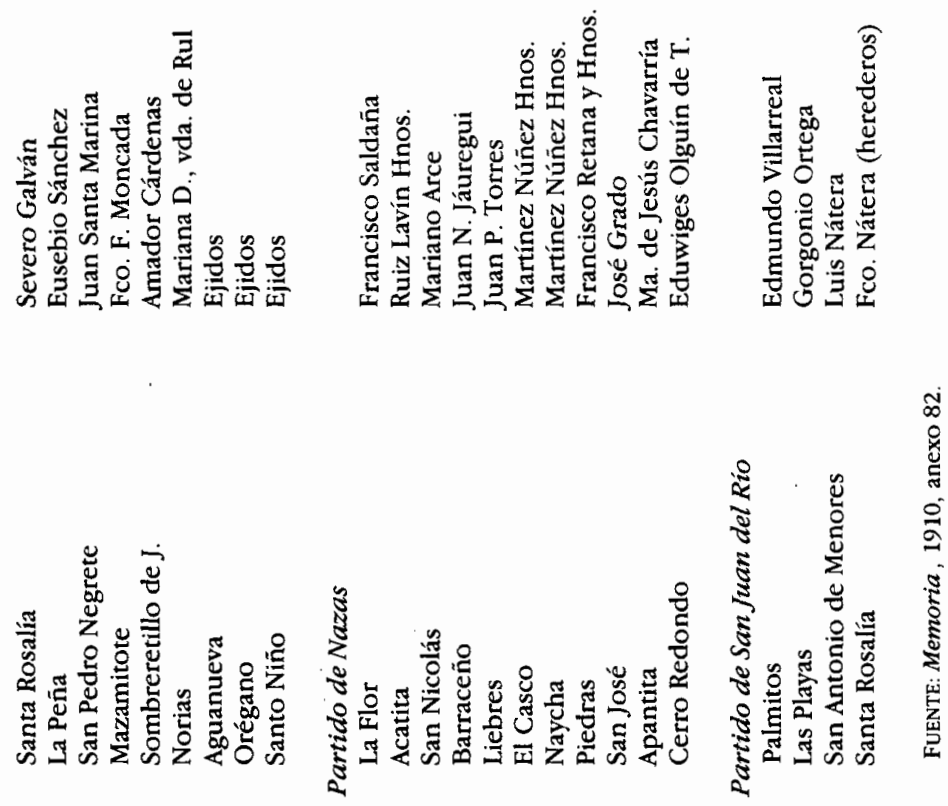
prometido con la poderosa empresa estadunidense, y de que ésta les había dado un sustancioso anticipo de 50000 pesos, incumplieron el contrato optando por vender su guayule, subrepticiamente, a la Compañía Explotadora de Caucho Mexicano que, como ya he señalado, era la más fuerte competidora de la Continental. En respuesta, ésta los boletinó en los periódicos oficiales de Zacatecas, Durango y Coahuila, responsabilizando civil y penalmente a los compradores. ${ }^{39}$

\section{EL GUAYULE EN TIEMPOS \\ DE LA REVOLUCIÓN}

Al inicio de la revolución, las disputas territoriales concluyeron -extraoficialmente-, cuando los vecinos ocuparon las haciendas; pero entonces el caos agravó la sobreexplotación y el tráfico ilegal del guayule. El abuso y poco cuidado para su propagación, casi terminaría por agotarlo en la segunda década del siglo XX.

Los conflictos políticos que involucraron al sector agrario disminuyeron la capacidad productiva de las tierras, pues la revolución dio ocasión a un revanchismo entre pobladores y hacendados que fue reseñado por varios periódicos. Durante 1911 los diarios $E l$ Telégrafo y La Evolución se ocuparon de los "escandalosos robos de guayule" de que estaba siendo víctima la hacienda de Santa Catalina del Álamo, estimando en más de 300000 pesos el monto de lo robado. Cuadrillas de hom-

3922,23 y 24 de marzo de 1911. bres armados penetraban en los terrenos de la hacienda, cortaban el guayule y lo conducían a Nazas para luego subastarlo públicamente entre agentes especiales enviados por las fábricas, los cuales adquirían la tonelada a mitad de su valor.

Los diarios hacían hincapié en que los clientes sabían perfectamente que el guayule era robado. El asunto era más grave de lo que hasta entonces se creía, pues los hurtos a las haciendas de Santa Catalina y Santa Inés eran cuantiosos y reiterados, además se supo que algunos jefes de acordada eran compradores de "chueco", y que el jefe político de Nazas también estaba involucrado en los ilícitos, pues cobraba por la expedición de pases para cortar guayule.

Los periódicos atacaban de continuo a las autoridades gubernamentales que parecían tener oídos sordos a las quejas de los afectados, algo indicativo de complicidad o de sumisión con las empresas extranjeras. Por añadidura, la escasez de fuerzas armadas dejó a los hacendados sin ninguna garantía. Durante la permanencia de las fuerzas maderistas en Durango, nada había podido hacerse para reprimir al bandolerismo en los partidos de Cuencamé y Nazas porque era solapado por aquéllas. Entre las fincas más castigadas estuvieron Santa Catalina del Álamo y Sombreretillos de Campa que, además, sufrieron el hurto de ganado menor, vacuno y caballar. Por otra parte, muchos ex revolucionarios se apoderaron de terrenos de las haciendas y comenzaron a explotarlos como cosa propia.

Según el periódico El Popular -31 de diciembre de 1911-, para evitar los escandalosos robos de guayule que es- 
taban sufriendo las haciendas de la región este de Durango, fueron movilizadas las fuerzas maderistas que, al mando de Jesús Agustín Castro, se encontraban en La Laguna. Otro de los focos del bandolerismo estaba localizado en Peñón Blanco, donde había investigadores que atizaban el odio de los peñoleros contra sus antiguos enemigos:

No hace mucho que un ex jefe maderista incitaba a los vecinos de Peñón Blanco a que se lanzasen contra Santa Catalina, asegurándoles que podían tomar terrenos de la hacienda porque habían obtenido sentencia favorable en un juicio que hace algunos años siguieron contra dicha hacienda. En poder de algunos de los medieros de la misma hacienda existian, hace poco tiempo, órdenes escritas y firmadas por un ex cabecilla revolucionario, diciéndoles que no dieran a la hacienda la parte de la cosecha que debían darle según el contrato, ya que todo era de ellos[...] Y a esos instigadores que hacen gala de audacia no se les persigue, por más que se ostenten a la luz del día y hacen propaganda de sus ideas anárquicas por medio de los periódicos y de hojas sueltas que circulan con profusión.

El estado anómalo creado por la revolución produjo ilegalidades, atropellos e irregularidades en las transacciones comerciales. Entre los muchos casos que se pudieran presentar está, como ejemplo, el de la señora Guadalupe $L$. viuda de Rodríguez y Josefina Rodríguez de Zubiría, esposa e hija, respectivamente, de Felipe Rodríguez, dueño, como ya se dijo, de la hacienda de Milpillas, quien poco antes de morir estableció un contrato con la Com- pañía Explotadora de Caucho Mexicano, a pesar de lo cual ésta no pagó los anticipos pactados ni se preocupó en llevar adelante la explotación convenida, causando a madre e hija "perjuicios incalculables". ${ }^{40}$ En vista de las circunstancias, señalaban las afectadas, Enrico Notholt les hizo "proposiciones racionales para el negocio del guayule", autorizando a la Compañía Hulera de Monclova a explotar los terrenos de su propiedad; sin embargo, al iniciar los trabajos de corte y embarque del arbusto, la Compañía Explotadora de Caucho Mexicano inició, ante las autoridades judiciales de San Juan de Guadalupe, procedimientos penales por robo de guayule, a pesar de tratarse de un asunto civil. Señalaban las quejosas que aquella compañía no estaba en posesión de los terrenos ni tenía trabajos de explotación, y que además había faltado al contrato que ahora quería hacer valer.

El juez de San Juan de Guadalupe ordenó el aseguramiento del guayule, sin embargo, poco duró en su encargo, siendo sustituido por otro que declaró que no había delito que perseguir por ser un asunto civil. Cuando Notholt se disponía a recoger el guayule, el juez, sustituido de nuevo, detuvo su devolución.

Todo parecía indicar que había un contubernio entre la Continental Mexican Rubber Company y el jefe político o el presidente municipal de San Juan de Guadalupe, por lo que las Ro-

${ }^{40}$ AHGED, carta de Guadalupe L. viuda de Rodríguez y Josefina R. de Zubiría a Luis Alonso y Patiño, ramo Cartas a gobernadores, 21 de diciembre de 1911, exp. sin clasificar. 


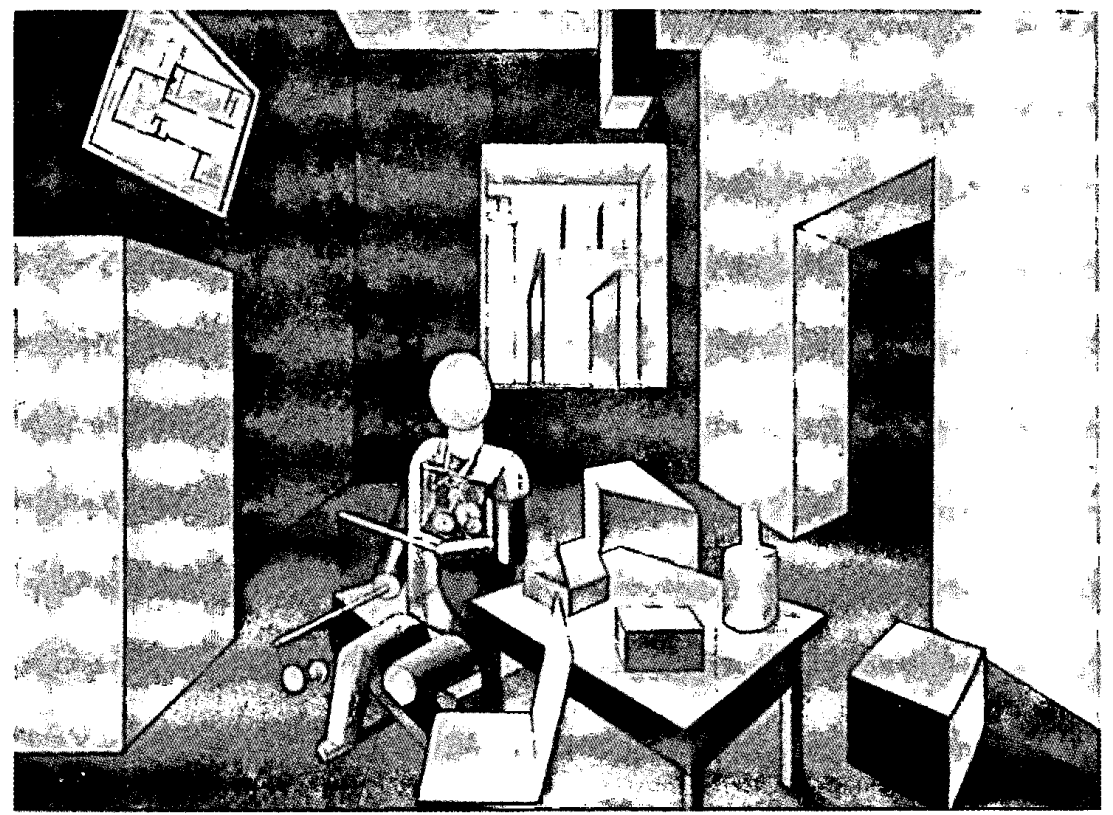

dríguez acudían al gobernador en busca de protección y ayuda:

la suerte de dos pobres mujeres está en las manos $[\ldots]$ de una compañía monopolizadora que tampoco tiene escrúpulos para satisfacer sus ambiciones $[\ldots]$ agradeceremos a usted que, inspirado en sus sentimientos de equidad y de justicia, se sirva protegernos en la esfera de sus atribuciones, cambiando las autoridades políticas que de usted dependan y recomendando que las judiciales obren con entera justicia, sin ver que es grande y poderosa la compañía acusadora y que somos desvalidas nosotras. ${ }^{41}$
El resultado final fue que en este caso, y a pesar de todo, la Compañía Explotadora de Caucho Mexicano se impuso, lo que ilustra cuán sumisas podían ser las autoridades cuando había poderosos intereses de por medio.

San Juan de Guadalupe se había convertido en otro de los blancos favoritos de extracción ilegal de guayule, por lo que se buscó formar una "guerrilla" para proteger los campos. A juicio del gobernador, una fuerza de cinco hombres era suficiente para mantener una buena vigilancia a condición de que fueran hombres de orden y no se em-

${ }^{41}$ Ibid. 
briagasen. ${ }^{42}$ Obviamente, la "sugerencia" del nuevo gobernador, Emiliano González Saravia, parecía estar encaminada a evitar la solución, pues cinco hombres eran insuficientes para vigilar tan dilatadas tierras. La mercancía hurtada en San Juan iba a parar al rancho de Molinos, situado en el partido de Nieves, Zac., donde se almacenaba para su posterior venta ilegal. Las denuncias de robo de caucho se volvieron cotidianas sin que -las más de las veces- los administradores de las haciendas afectadas pudieran recuperar sus mercancías. Cuando era interceptado un cargamento era difícil comprobar su procedencia y propiedad, por lo que en muchas ocasiones los inculpados quedaban en libertad.

El jefe político de Cuencamé reportó que vecinos de la hacienda de Penón Blanco, por ejemplo, extraían guayule de un rancho anexo de la hacienda llamado Acatita o Acatitlán, alegando que lo hacían con autorización de unas mesas directivas de representantes del municipio. Como ya se dijo, el partido de Cuencamé era un punto neurálgico de disputas agrarias que guardaban condiciones semejantes en Ocuila, Santa Catalina y Peñón. Durante la revolución, los moradores de los pueblos entraron en posesión de las tierras, sin embargo, para agravar aún más el estado de cosas, los nuevos dueños de la situación se negaron a pagar los impuestos aplicados al guayule, ya que consideraban que la revolución

42 AHGED, Alejandro Gaytán, jefe político de San Juan de Guadalupe, a Emiliano G. Saravia, ramo Cartas a gobernadores, 27 de octubre de 1911, exp. sin clasificar. no se había hecho para asignar imposiciones. Por otro lado, era conocido el hecho de que Calixto Contreras, dirigente de los pueblos de Ocuila en Cuencamé y principal jefe revolucionario de la zona, había autorizado la extracción de guayule de las haciendas ubicadas en el territorio bajo su control.

Esta situación anómala, que afectaba gravemente a la economía estatal, a las propiedades y a muchas de las compañías guayuleras -otras desde luego resultaron beneficiadas con las compras clandestinas-, propició que gobierno y empresas trabajaran coordinadamente para evitar la expoliación de la goma. De ese modo, cada compañía pagó el mantenimiento de cuerpos de seguridad llamados acordadas o guerrillas, formados hasta por diez hombres, para vigilar cada uno de los puntos del estado en los que tenían intereses. La Compañía Explotadora de Caucho Mexicano, S. A. nombró a José María Patoni comandante de su guerrilla en San Juan de Guadalupe. ${ }^{43}$

La situación llegó a tal punto, que incluso los robos de caucho se con. virtieron en materia de asuntos diplomáticos. El embajador estadunidense, Henry Lane Wilson, intervino ante el ministro de Relaciones Exteriores, Francisco León de la Barra, para proteger los intereses de la Continental Mexican Rubber Company. ${ }^{44}$

${ }^{43}$ AHGED, Ricardo Reyes, representante de la Compañía Explotadora de Caucho Mexicano, S. A. en Torreón, Coah., a Luis Alonso y Patiño, ramo Cartas a gobernadores, 12 de enero de 1912.

${ }^{44}$ AHSRE, exp. 12-23-96, 11 de abril de 1912 
Por otra parte, el subsecretario de Relaciones Exteriores de México, Leopoldo Rebollar, informaba al secretario de Guerra y Marina que el jefe de armas en Torreón dificultaba a las compañías extranjeras -especialmente a la American Smelting and Refining Co. y a la Continental- el transporte de los empleados que deseaban dejar la ciudad. ${ }^{45}$

En 1914, año de grandes batallas y triunfos revolucionarios, las companías establecidas en La Laguna vivieron sus peores momentos; por ejem. plo, la Explotadora de Caucho Mexicano, S. A. fue intervenida por órdenes del jefe de armas en Saltillo y dada en administración a Miguel R. Ávila. El encargado de Negocios inglés, T. B. Hohler, se dirigió al entonces secretario de Relaciones Exteriores, Isidro Fabela, para informarle que los revolucionarios habían afectado gravemente las instalaciones de la empresa, al utilizar la tubería de cobre para fabricar bombas y una de las chimeneas para la construcción de un fanal eléctrico, causando su paralización durante ocho meses. El diplomático denunciaba, además, que el jefe de armas pretendía ser quien vendiera la materia prima a la empresa.

Julio Schroeder e Ignacio Treviño, dos de los accionistas de la Explotado$\mathrm{ra}$, provocaron intencionalmente un incendio en la fábrica, hecho por el que fueron encarcelados. Los constitucionalistas estaban haciendo pagar a la Explotadora, el apoyo que había brindado a los federales al permitirles alojarse en la fábrica y venderle a Huerta alrededor de 40000000 de cartuchos.

${ }^{45}$ Ibid.
Durante la revolución, hubo muchos generales que comenzaron a explotar el caucho en forma ilegal, entre ellos Francisco Murguía, quien valiéndose de su investidura como jefe de operaciones militares, se agenció terrenos guayuleros en el estado de Zacatecas, para luego vender la materia prima al mejor postor.

En un reporte presentado por la Intercontinental Rubber Company, destacó que:

La perturbada situación en México impidió que la Continental Mexican Rubber Co. pudiera trabajar a toda su capacidad [...] Luego de haber estado completamente paralizada por dos años, la fábrica reanudó sus operaciones en una escala menor y con frecuentes interrupciones, a partir del 1 de noviembre de 1917.46

\section{CONCLUSIONES}

A fines del siglo XIx, el guayule no sólo era considerado carente de valor por los terratenientes, sino una plaga por la que tenían que pagar para que fuera removida. El desarrollo de la industria del guayule entre 1902 y 1910 contribuyó al crecimiento agrícola, industrial y comercial de varios estados norteños.

La Laguna fue el centro de expansión del guayule en México, el valor de las tierras agrícolas de la región, que de por sí se había ido a las nubes, siguió en ascenso: las tierras secas, antes consideradas marginales o sólo adecuadas para el pastizaje de mulas, triplicaron su valor en tres años, naciendo

${ }^{46}$ Supplement, 1920. 
fortunas con la venta de estas tierras "sin valor". Hacia 1906 el guayule se convirtió en la exportación más valiosa de La Laguna, destronando al algodón de su reinado.

A pesar de la inquietud manifiesta porque no se conocían métodos para propagar el arbusto, los grandes capitales invertidos y la experiencia adquirida alentaban perspectivas optimistas para encontrar una solución. En México, Carlos Patoni, Salvador Creel y Mario Calvino, entre otros, efectuaron los primeros ensayos para su propagación buscando, incluso, sustituir con el cultivo del guayule en las tierras menos pródigas la producción algodonera.

Antes de finalizar la primera década del siglo XX, ya existían múltiples compañías y se habían construido numerosas plantas de procesamiento en La Laguna. La Compañía Anglo Mexicana y la Compañía Explotadora de Caucho Mexicana, controlada por alemanes, erigieron fábricas en Jimulco; la Mexican Crude Rubber Company, estadunidense, y la Compañía Mexicana Internacional Guayulera, S. A., alemana, en Viesca; la Compañía Guayulera de Torreón, propiedad del licenciado Manuel Garza Aldape, la National Rubber Company, estadunidense, y la Clement Jacque, manejada por franceses, en Torreón. Había varias en Gómez Palacio, entre las que destacaba la Fábrica de Hule de Otto Katterfield, alemán, pionero en el desarrollo del guayule, y la administrada por la casa Delafon Rubber Company.

Sin duda, las tres más grandes empresas guayuleras en México fueron la Compañía Explotadora Coahuilense,
S. A., propiedad de los Madero; la Continental Mexican Rubber Company controlada, como ya se mencionó, por un grupo de capitalistas estadunidenses encabezados por John D. Rockefeller, Jr., y la Explotadora de Caucho Mexicano, controlada por capitales alemanes y británicos.

$\mathrm{Al}$ igual que con su participación en las fundidoras, los Madero representaron la única empresa mexicana de importancia en una industria dominada prácticamente por extranjeros. La nueva generación de agricultores combinó el talento práctico con el empresarial, y cada cual sacó provecho de las ventajas del ferrocarril y el riego para adquirir y desarrollar propiedades en un amplio espectro regional que les permitió diversificar sus negocios. El auge económico trastocó, sin embargo, los cimientos del orden social mediante una combinación de factores políticos y económicos que llevarían a la lucha armada y, con ella, al debilitamiento y posterior abandono de una importantísima fuente de ingresos y trabajo. La revolución fracturó a la elite norteña golpeándola severamente en su economía agrícola. Muchos salieron del país; otros se radicaron en la ciudad de México, y los más visionarios vendieron antes de que el reparto agrario acabara de asestar el golpe final a su economía.

\section{FUENTES PRIMARIAS}

\section{ARCHIVOS}

AGNCM Archivo General de Notarias, Ciudad de México. 
AHGED Archivo Histórico del Gobier. no del Estadio de Durango.

AHSRE Archivo Histórico de la Secretaría de Relaciones Exteriores.

APD Archivo Porfirio Díaz.

IEDS-ANEC Instituto Estatal de Documentación, Saltillo, Archivo de No. tarías del Estado de Coahuila.

RPP Registro Público de la Propiedad, Torreón, Coah.

\section{HEMEROGRAFÍA}

-El Nuevo Mundo, 1907, Torreón, Coah. -El Telégrafo, 1911, Durango.

-La Evolución, 1906, 1911, Durango.

-Periódico Oficial del Gobierno del

Estado de Coabuila, 1911.

-Periódico Oficial del Gobierno del

Estado de Durango, 1910, 1911.

-Periódico Oficial del Gobierno del

Estado de Zacatecas, 1911.

\section{BIBLIOGRAFÍA}

-Cano, Gloria y Miguel Vallebueno, "El campo y la tenencia de la tierra (18801910)" en Durango (1840-1915). Banca, transportes, tierra e industria, UANL/UJED, Monterrey, N. L., 1995 (Col. Historia Económica del Norte de México, siglos XIX y $\mathrm{Xx}$, núm. II).

-Catálogo cartográfico, Mapoteca Manuel Orozco y Berra, Dirección General del Servicio Meteorológico Nacional-SARH, México, 1985, 2 vols. (Col. Pastor Rouaix).

-Collier, Peter y David Horowitz, Los Rockefeller. Una dinastia americana, Tusquets Editores, Barcelona, España, 1987 (Col. Andanzas).

-Cosío Villegas, Daniel, Historia Moder. na de México. El porfiriato. Vida eco- nómica, Editorial Hermes, México, 1974, 2 vols.

-Guayule, reencuentro en el desierto, Centro de Investigación en Química Aplicada-Comisión de las zonas Áridas-CONACYT, 3a. ed., México, s. a.

-Memoria presentada al H. Congreso del estado por el gobierno del mismo, sobre los actos de la administración pública durante el periodo del 16 de septiembre de 1904 al 16 de septiembre de 1906, Imprenta del Gobierno, Durango, 1906.

-Memoria presentada al $\mathrm{H}$. Congreso del estado por el gobierno del mismo, sobre los actos de la administración pública durante el periodo del 16 de septiembre de 1908 al 16 de septiembre de 1910, Imprenta del Gobierno, Durango, 1910, anexo 82.

-Meyers, William K., Forja del progreso, crisol de la revuelta. Los orígenes de la revolución mexicana en la comarca lagunera, 1880-1911, INEHRM/UIA/IED, Coahuila, 1996.

-Orozco Wistano, Luis, Legislación y jurisprudencia sobre terrenos baldios, Imprenta de El Tiempo, México, 1895.

-Supplement to the Market Review, Hughes \& Dier, Nueva York, 1919-1920.

-Vidal y Flor, Luis A., Fernando Pimentel y Fagoaga. Esbozo biográfico, Tipografía de Bouligny \& Schmidt Sucs., 1907.

-Villa, Guadalupe, "Al este de Durango, elites, clases sociales y rebelión", ponencia presentada en el XXI Congreso Internacional de LASA, Chicago, Ill., 24-26 de septiembre de 1998.

-Walker, "Homegrown revolution: Santa Catalina del Alamo y Anexas and agrarian protest in eastern Durango, Mexico, 1897. 1913", Hispanic American Historical Review, Duke University Press, vol. 72, núm. 2, 1992. 